Pontifícia Universidade CATÓLICA do RIO dE JANEIRO Influência do Instagram na Escolha de
Restaurantes Ana Carolina Camilo M. da Rocha Trabalho de Conclusão de Curso Centro de Clências SOCIAIS - CCS Departamento de Administração Graduação em Administração de Empresas 


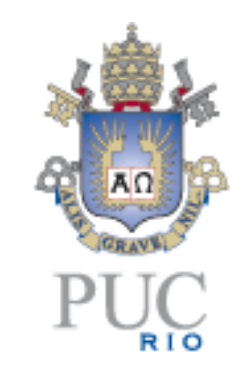

Ana Carolina Camilo M. da Rocha

\title{
Influência do Instagram na Escolha de Restaurantes
}

\author{
Trabalho de Conclusão de Curso
}

Trabalho de Conclusão de Curso, apresentado ao programa de graduação em Administração da PUC-Rio como requisito parcial para a obtenção do título de graduação em Administração.

Orientador(a): Barbara Levy

Rio de Janeiro

Junho de 2020. 
"A genialidade é 1\% inspiração e 99\% transpiração" - Thomas Edison 


\section{Agradecimentos}

Dedico esse trabalho a Ana Carolina do sétimo ano do fundamental, que sempre duvidou de si mesma e nunca se encaixou tão bem nos padrões tradicionais de ensino. A mesma que no segundo ano do ensino médio, não desistiu de se formar no colégio que tanto amava. Prestes a se formar na faculdade, queria dizer que esse período não foi como esperava e os caminhos profissionais também não, mas nem sempre tudo vai dar certo e que os planos geralmente não saem como o queremos, mas o universo tem direções melhores para mostrar. O sonho pela indústria da beleza continua e você ainda trilhará um lindo caminho nele, mas até lá você está descobrindo muita coisa que nunca tinha imaginado. Lembre-se sempre que você é capaz de muita coisa, mesmo que todos ao seu redor duvidem. Claro que sozinha não conseguiria chegar até aqui, então dedico esse trabalho a todos que trilharam esse caminho comigo, me orientando e aconselhando com tanto carinho. Muito obrigado a minha família, amigos e namorado, que sempre estiveram do lado em todos os momentos, me apoiando em cada decisão. Agradeço a todos os funcionários do IAG, que sempre com toda atenção estiveram presentes desde 2016 me ajudando. Queria fazer um agradecimento especial a minha orientadora, professora Barbara Levy, que fez parte dos últimos períodos de curso e nunca me deixou desistir em nenhum momento, com muita delicadeza, cuidado e carinho. Não poderia ter pessoas melhores para me apoiarem nessa trajetória. 


\section{Resumo}

Rocha, Ana Carolina Camilo M. Influência do Instagram na Escolha de Restaurantes. Rio de Janeiro, 2020. 39p. Trabalho de Conclusão de Curso - Departamento de Administração. Pontifícia Universidade Católica do Rio de Janeiro.

O Instagram nasceu como uma rede social para postar fotos e hoje é considerado uma plataforma de negócios. Atualmente é uma das principais responsáveis em influenciar o processo de tomada de decisão nos diferentes mercados. Esse estudo pesquisou de que maneira os consumidores são influenciados na escolha de restaurantes por meio do uso do Instagram, utilizando, como método, uma pesquisa qualitativa com 20 jovens cariocas. Dentre os principais achados podemos destacar: a importância da plataforma como divulgadora de informação, a influência do visual da foto na hora de despertar o interesse e as conexões que os usuários criam com outros perfis.

\section{Palavras- chave} Consumidor

Restaurantes, Instagram, Rede Social, Processo de Compra do

\section{Abstract}

ROCHA, Ana Carolina. Instagram influence on the choice of restaurants. Rio de Janeiro, 2020. 39p. Trabalho de Conclusão de Curso - Departamento de Administração. Pontifícia Universidade Católica do Rio de Janeiro.

Instagram was born as a social network to post photos and today it is considered a business platform. Currently, it is one of the main responsible for influencing the decision-making process in different markets. This study researched how consumers are influenced in choosing a restaurant by using Instagram, having, as a method, a qualitative research with 20 young people from Rio de Janeiro. As main findings we can highlight the importance of the platform as an information disseminator, the influence of the visual of the photo in arousing interest and the connection created by users with other profiles.

Key-words

Restaurants, Instagram, Social Midia, Consumer Buying Process 


\section{Sumário}

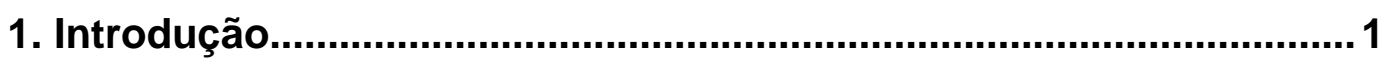

1.1. Introdução ao tema e ao problema do estudo........................... 1

1.2. Objetivo do estudo ...............................................................

1.3. Delimitação e foco do estudo................................................. 3

1.4. Justificativa e relevância........................................................... 3

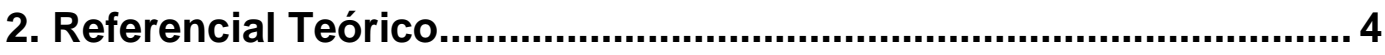

2.1. Processo de Tomada de Decisão do Consumidor....................... 4

2.1.1. Tipos de Envolvimento............................................ 5

2.1.2. Processo de Tomada de Decisão................................6

2.1.3. Emoção e Consumo................................................ 9

2.2. Influências Sociais................................................................ 10

2.2.1. Influência dos grupos de referência............................10

2.2.2. Influência do Instagram........................................ 11

\section{Metodologia}

3.1. Método de pesquisa utilizado .............................................13

3.2. Coleta de informações...................................................... 13

3.3. Tratamento e análise dos dados.............................................15

3.4. Limitações do método...................................................... 15

\section{Apresentação e análise dos resultados}

4.1. Perfil dos Entrevistados................................................... 17

4.2. Uso da rede social............................................................ 18

4.3. Processo de tomada de decisão..............................................20

5. Conclusões.

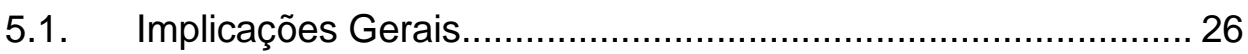

5.2. Sugestões de futuras pesquisas...........................................27 
Referências Bibliográficas................................................................ 28

Apêndice: Roteiro da pesquisa......................................................33 


\section{Introdução}

\subsection{Introdução ao tema e ao problema do estudo}

Os hábitos de consumo mudam de acordo com o momento e fatores internos e externos de cada indivíduo (SOLOMON, 2016). A sociedade brasileira modificou sua forma de consumir nos últimos anos com a expansão das redes sociais, as quais têm grande influência nos nossos novos hábitos de consumo (DINO, 2018). A dinâmica de mundo que vivenciamos hoje nos permite ter cada vez menos tempo disponível, principalmente para tarefas domésticas, como cozinhar. Segundo o IBGE (2018 apud SILVEIRA, 2019), os brasileiros gastam em média um terço das despesas de alimentação com comida fora de casa, 8,7\% a mais do que na última pesquisa em 2003. Esse contexto fez o mercado de food service $^{1}$ tivesse um crescimento considerável na receita nominal no último ano, cerca de $6,9 \%$ em comparação ao ano de 2018. Alguns fatores foram determinantes para esse crescimento, como a queda de $12 \%$ no desemprego e avanço do índice de confiança do consumidor (DEVISATE, 2019). Além disso, com a atual conjuntura causada pela pandemia do corona vírus, alguns restaurantes se reinventaram para continuar levando não só a comida, mas a experiência para seus clientes. Os estabelecimentos enviam suas comidas, semi prontas, e ensinam como fazer através de vídeos interativos no Instagram ou até mesmo por carta junto com a encomenda.

Outros fatores que impactaram no mercado de bares e restaurantes foram a entrada da mulher no mercado de trabalho, as máquinas tomando lugar de humanos, entre outros, os quais fizeram com que as pessoas passassem mais tempo fora de casa do que dentro dela (TAGGART, 2018). O crescimento desse segmento tem a ver com as mudanças citadas anteriormente, mas grande parte do salto dos últimos anos foi consequência da entrada das redes sociais no contexto (BBC NEWS BRASIL, 2018).

No final do século $X X$, a tecnologia começou a ter espaço no cotidiano das pessoas e fez com que a forma de obter informação fosse alterada. Por meio de,

\footnotetext{
${ }^{1}$ Food Service signica mercado de alimentação fora do lar (SANTOS, 2018).
} 
por exemplo, celulares, as pessoas começaram a interagir uma com as outras, sem ao menos se conhecer e, nesse cenário, surgiram os influenciadores digitais. Eles passaram a ditar uma nova forma de consumo através da transformação das suas vidas em vitrine de mercadoria, fazendo com que os seus seguidores desejem ser eles utilizando e comprando o que é mostrado (SÁ, 2017).

As empresas têm se aproveitado das ferramentas digitais como uma maneira de criar vínculo, estabelecer comunicação e interação de maneira direta e rápida na mensagem compartilhada com o público de interesse. O progresso das tecnologias proporcionou inúmeras maneiras de se estabelecer um espaço de diálogo e as organizações estão aprendendo sobre essas tendências e sobre as possibilidades de explorar 0 que as novas mídias de relacionamento prometem (SARAIVA, 2019, p. 486).

Segundo a reportagem da BBC News Brasil (2019), as pessoas passam cerca de três horas e meia do dia usando diversos aplicativos de interação, sendo o Instagram um dos mais utilizados. O aplicativo do Instagram foi criado em 2010 por Kevin Systrom e Mike Krieger, e se popularizou dois anos depois. A rede social possuía 66 milhões de usuários só no Brasil em 2018, sendo o segundo país do mundo com mais perfis na plataforma, atrás apenas dos Estados Unidos (AGRELA, 2019).

Conforme matéria publicada na Época Negócios (BBC NEWS BRASIL, 2018), uma boa foto no Instagram pode provocar um aumento significativo no consumo de um restaurante. Muitas pessoas vão aos locais e escolhem o que vão comer pelas fotos vistas na rede social. As marcas hoje já estão mudando até o jeito que apresentam os pratos para ficarem cada vez mais instagramáveis ${ }^{2}$.

Em vista desse contexto, o estudo procurou entender como o Instagram influencia a tomada de decisão dos consumidores em relação à escolha de restaurantes.

\subsection{Objetivo do estudo}

O objetivo dessa pesquisa é compreender como ocorrem as influências sociais por meio do Instagram na tomada de decisão de restaurantes por consumidores jovens.

\footnotetext{
2 Instagramável significa algo bem decorado e interessante que desperte a vontade de fotografar e publicar no Instagram (MORAIS, 2018).
} 
Para tanto, foi analisado como é o processo de tomada de decisão do consumidor até ele chegar na escolha final por um restaurante, entendendo como ele é envolvido no processo e como é afetado pelas suas emoções. Mais especificamente, foi pesquisado como o indivíduo é impactado pelas influências sociais, em particular por meio do aplicativo do Instagram.

\subsection{Delimitação e foco do estudo}

O estudo teve como foco a influência da rede social Instagram na escolha de restaurantes. Outras possíveis influências no processo de tomada de decisão não foram pesquisadas, mesmo sabendo que o Instagram não seria o único agente influenciador.

A pesquisa se restringiu a estudar apenas refeições feitas fora de casa, a qual os entrevistados tinham o poder de escolha do local. Ela foi realizada durante o mês de maio de 2020 com jovens do Rio de Janeiro, sem delimitação de gênero.

\subsection{Justificativa e relevância}

O Instagram é uma tendência em diversos segmentos para os próximos anos e tende a ter um alto investimento pelas indústrias (LEITE, 2019). O estudo contribui para entender de que modo o movimento pode gerar resultados positivos na indústria de restaurantes, além de poder servir a outros setores que possam utilizar o mesmo meio para influenciar as escolhas dos consumidores. 


\section{Referencial Teórico}

Neste tópico são apresentados e discutidos aspectos conceituais e estudos relacionados ao tema e ao estudo em investigação e que servirão de base para a análise realizada.

Esta seção está dividida em duas partes. A primeira trata sobre a questão da tomada de decisão de consumo, abordando os aspectos de envolvimento do consumidor, a decisão e o impacto da emoção, até o cliente chegar ao seu produto. A segunda parte mostra a questão das influências sociais e como elas impactam no comportamento do consumidor. A partir disso é apresentado como o Instagram pode influenciar no processo de compra.

\subsection{Processo de Tomada de Decisão do Consumidor}

A tomada de decisão é uma forma de solucionarmos um problema. Para que isso seja feito existe um repertório de estratégias. Dependendo de cada situação o processo construtivo é diferente: para decisões que envolvem maior risco é necessária uma abordagem mais racional, ao contrário de compras habituais, que não tem essa demanda (SOLOMON, 2016). De acordo com Gilbert Churchill e Paul Peter (2012), quando o produto tem um preço elevado, características complexas, novas e até mesmo diversas opções no mercado, o cliente investe mais tempo e dedicação na hora da escolha.

De acordo com Michael Solomon (2016, p. 41), a tomada de decisão pode ser afetada pelo envolvimento de cada um em relação ao produto, acarretando resultados diferentes. Referenciando-se a Richins et al. (1992 apud SOLOMON, 2016), o autor disserta sobre a existência de tipos de envolvimento: envolvimento com o produto, com a mensagem e o envolvimento situacional. $\mathrm{O}$ primeiro tem vínculo com o produto específico; já o envolvimento com a mensagem está ligado à publicidade; e por fim, o envolvimento com a situação é a questão do ambiente. Além disso, decisões são diferentes para cada indivíduo, já que cada um percebe riscos de formas diferentes (SCHIFFMAN \& KANUK, 2000).

Além disso, a tomada de decisão envolve um processo cognitivo, o qual resulta em uma série de etapas para a escolha de um produto. Essas etapas 
podem ser classificadas como reconhecimento do problema, busca de informação, avaliação de alternativas, escolha do produto e avaliação pós compra. Ademais, esse processo pode ser afetado, nas diferentes fases, por questões emocionais que afetam de forma positiva ou negativa (SOLOMON, 2016).

De acordo com Goulart et al. (2019), a tecnologia está em constante mudança assim como o comportamento do consumidor no processo de tomada de decisão.

\begin{abstract}
As empresas devem estar cada vez mais presentes nas mídias sociais, fazendo investimentos nas suas atuações nestas plataformas, para que elas se mantenham mais próximas dos consumidores, podendo então influenciar na decisão de compra dos seus clientes (SOUZA, 2018, p. 52).
\end{abstract}

\title{
2.1.1. Tipos de Envolvimento
}

Como visto, a tomada de decisão do consumidor leva em consideração algum grau de envolvimento com o produto (RICHINS et al, 1992 apud SOLOMON, 2016), diferente para cada pessoa dependendo das suas necessidades, valores e interesses. Abrangeremos, assim, a citada tipificação para esse envolvimento: com o produto, com a mensagem e situacional (apud SOLOMON, 2016, p.41).

O envolvimento com o produto é a relação do consumidor com o que ele vai efetivamente consumir, podendo ser algo físico ou um serviço. Cada decisão feita sobre a escolha de um produto tem riscos e quanto mais risco o consumidor percebe, mais ele cria envolvimento. Existem diversos tipos de risco que podem ser monetário, funcional, físico, social e até mesmo psicológico, mas eles nunca irão ser iguais para clientes diferentes: dependendo de cada cliente ele pode variar de intensidade (SOLOMON, 2016).

O segundo tipo de envolvimento é com a mensagem, desenvolvido principalmente pela mídia, tanto online quanto off-line. As empresas, quando fazem algum tipo de publicidade, procuram sempre trazer alguns aspectos que chamem a atenção das pessoas, através de estímulos e referências, para que possam envolver o cliente com o que quer ser transmitido (SOLOMON, 2016).

Um exemplo de fonte para envolvimento com a mensagem é o Instagram, atual rede social com maior quantidade de usuários ativos e que interagem dentro da plataforma, fazendo parte do dia-a-dia das pessoas. Através dele, os consumidores se aproximam das marcas e de seus interesses, criando uma interação do consumidor com a empresa, permitindo o desenvolvimento em 
conjunto dos produtos. A plataforma transmite, por meio de fotos e vídeos, a mensagem a qual cada um pode ou não se identificar (SANTOS, 2016). Segundo Mariana Lima e Andre Carlos (2018), os restaurantes utilizam as mídias sociais como um canal de relacionamento, divulgando seus serviços e aproximando os laços com os seus clientes.

As interações entre consumidores e marcas/produtos nas redes sociais estão a ganhar cada vez mais impacto sobre o comportamento do consumidor em comparação com as restantes ferramentas tradicionais de marketing e publicidade (PEREIRA, 2018, p. 11).

Por fim, existe o envolvimento situacional que, para Michael Houston e Michael Rothschild (1977), provém da situação em que o cliente se encontra no momento da compra, relacionado com ambiente externo, dependendo de dois estímulos: estímulos relacionados ao objeto e estímulos relacionados com o ambiente. O primeiro é relacionado com preço, complexidade e frequência de compra, já o segundo age sobre o psicológico de cada pessoa, o qual em uma situação onde o cliente esteja passando mal ou até mesmo estressado pode afetar na compra. De acordo com Raj Arora (1982), clientes que estejam acompanhados por outra pessoa no momento da compra podem ter envolvimento diferente com o produto de acordo com a percepção do outro.

\subsubsection{Processo de Tomada de Decisão}

O processo de tomada de decisão é um conjunto de estágios, nos quais cada pessoa reúne o máximo de informação possível, calcula os prós e contras de casa situação e chega a um resultado que ela acredita ter maiores chances de ser satisfatório. Essas etapas são: reconhecimento do problema, busca de informações, avaliação das alternativas, escolha do produto e avaliação póscompra (SOLOMON, 2016).

Figura 1: Etapas da tomada de decisão do consumidor

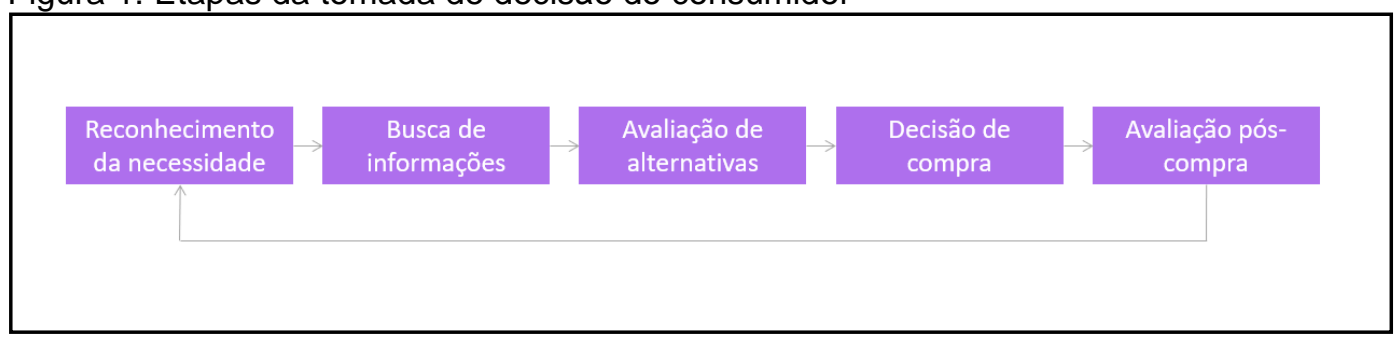

Fonte: SOLOMON, 2016, p.48 
O primeiro estágio desse processo, de acordo com Solomon (2016), ocorre quando existe uma diferença significativa entre o estado que é desejado para o estado que a pessoa se encontra e precisamos achar uma solução para esse problema. O reconhecimento do problema pode ocorrer de duas formas:

Reconhecimento da Necessidade: quando existe uma um decrescimento da qualidade a qual já está acostumado;

Reconhecimento da Oportunidade: quando a expectativa aumenta e cria-se um patamar de estado ideal.

Figura 2: Reconhecimento do problema: mudanças no estado real ou ideal

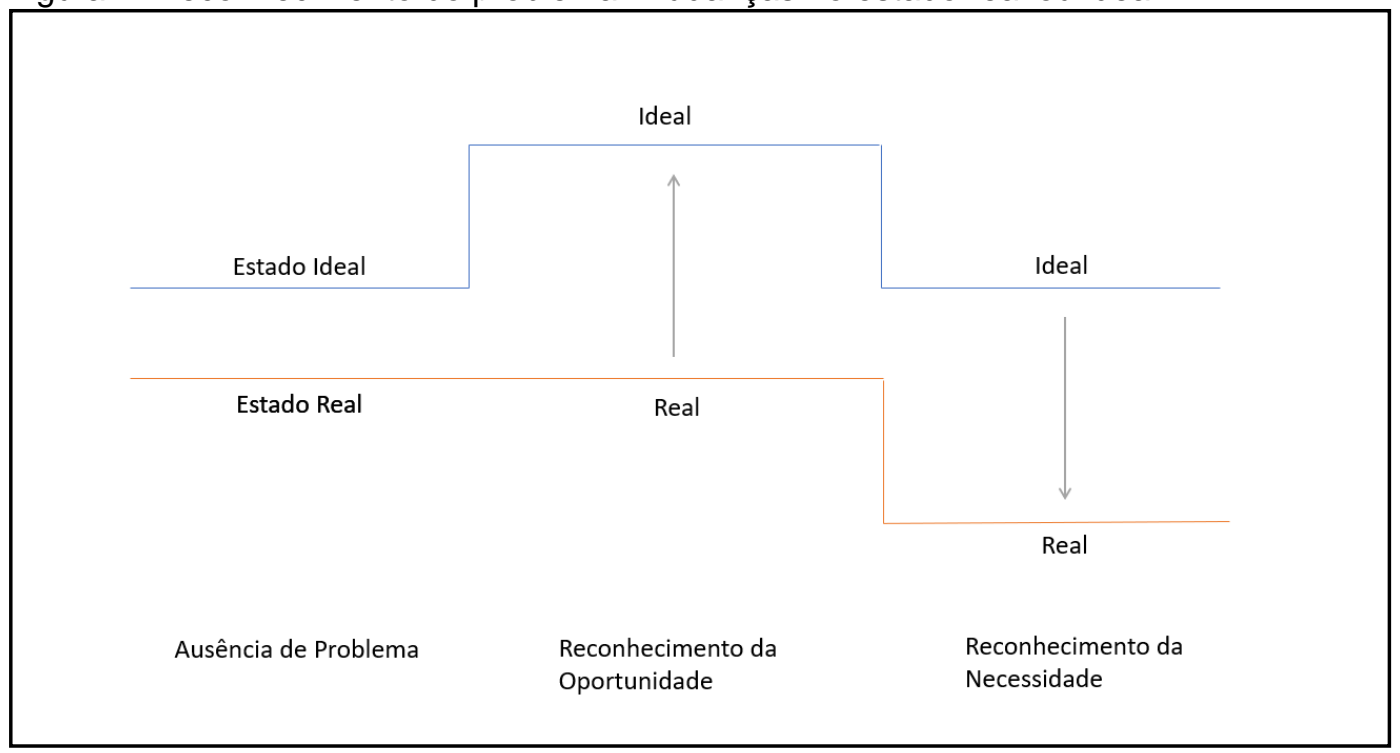

Fonte: SOLOMON, 2016, p.49

Segundo Solomon (2016), a busca de informação é o segundo passo e consiste em procurar no mercado dados para o ajudarem a tomar a decisão mais adequada. Na maioria das vezes essa pesquisa é feita somente quando sentimos a necessidade/reconhecemos o problema, primeira etapa comentada anteriormente. Entretanto, existem consumidores, chamados pelo autor de veteranos, que fazem essas pesquisas por diversão ou atualização pessoal. $A$ busca pelas informações está sempre atrelada à memória que construímos ao longo da vida, independentemente de ser veteranos ou não. Essa busca, de acordo com o autor, pode ser feita internamente, isso é, usando a memória, agrupando informações sobre as alternativas, e através de pesquisa externa, obtendo informações de amigos, comerciais ou até mesmo por observação. Thaler (2010, p.206) comenta também, conforme citado por Solomon (2016, p.50), que o volume de pesquisa depende do quão a compra é importante para cada indivíduo. 
Fatores como idade, conhecimento prévio, sexo, a representatividade do produto para cada um, entre outras influências, podem gerar mais ou menos busca.

Além disso, com o mundo online, existem as pesquisas via internet. Os "cibermediadores" são aplicativos ou sites que selecionam todos os produtos em diversas lojas, fazem uma filtragem e mostram para o cliente os melhores preços e avaliações, para que possa avaliar de maneira mais eficiente (HOTZ, 2009 apud SOLOMON, 2016, p.51). De acordo com Frigo et al. (2004), os agentes inteligentes desempenham várias funções em ambientes bastantes dinâmicos. No mundo online eles captam padrões do ambiente, tentando auxiliar o usuário. Isso faz com que, de acordo com o comportamento de cada perfil, diferentes produtos serão exibidos.

Em seguida é iniciado o processo de avaliação das alternativas, no qual as escolhas em potencial são avaliadas, sendo usados dois estágios de seleção: conjunto evocado e conjunto consideração. O conjunto evocado são os produtos ou marcas, que o consumidor associa para um determinado tipo de produto (SCHIFFMAN \& KANUK, 2000). De acordo com Solomon (2016), o conjunto de considerações são as marcas que o consumidor de fato considera na hora de comprar.

Solomon (2016) comenta que os consumidores que tenham hábitos de consumir um tipo de produto consideram poucas alternativas, mesmo com a quantidade de oferta que temos hoje em dia. As formas que categorizamos uma marca ou um produto influenciam na avaliação. Cada pessoa utiliza um critério de avaliação diferente, já que cada uma determina pesos distintos para cada atributo, de acordo com suas necessidades. Segundo o autor, decisões habituais e emocionais podem ser rejeitadas quando não são consideradas adequadas, utilizando a regra não compensatória com uma classificação de importância (SOLOMON, 2016). Assim, os mesmos produtos com diferentes importâncias geram resultados diferentes.

A penúltima etapa consiste na escolha do produto, período onde a decisão final é tomada, reunindo e avaliando as opções mais relevantes levantadas. Esse processo pode variar dependendo de alguns fatores ditos anteriormente, os quais podem ser rápidos e sem muitos processos complexos ou com muita atenção e pensamento racional (CHURCHILL JR \& PETER, 2012).

Por fim, segundo Solomon (2016), a última etapa consiste na prova do produto escolhido e em avaliar se ele atendeu as expectativas, chamada de avaliação pós-compra. De acordo com Gilbert Churchill Jr e Paul Peter (2012), essa fase é decisiva para os profissionais de marketing, pois é nesse momento 
que o consumidor reflete sobre voltar a comprar da marca ou deixá-la. Além disso, os próprios consumidores podem influenciar outras pessoas a terem o mesmo pensamento. Os autores também comentam sobre a dissonância cognitiva que acontece na compra de itens com alto valor, o qual a pessoa sente um remorso, o que leva a ponderação dos benefícios e a procura de informações que apoiem a decisão tomada (CHURCHILL JR \& PETER, 2012).

\subsubsection{Emoção e Consumo}

O consumo sempre está atrelado à emoção. Muitas das decisões que são tomadas têm influência dos sentimentos. Segundo cientistas (MURO\& MURRAY, 2012; MOGILNER et al., 2012 apud SOLOMON, 2016), reações não processadas são denominadas de afeto, que pode ser positivo ou negativo. O primeiro tem relação com a pessoa se sentir bem com o produto ou até mesmo com a marca, podendo desembolsar valores altos pelo produto de uma lovemark ${ }^{3}$. Por outro lado, existe o aspecto negativo, o qual o cliente não se sente bem em consumir determinado produto por diversos motivos, gerados principalmente pelos sentidos, como, por exemplo, odor desagradável. (SOLOMON, 2016).

Conforme Solomon (2016), as mídias sociais envolvem muita emoção do usuário, o qual compartilha sentimentos específicos e momentâneos, positivos ou negativos, através de emoticons ${ }^{4}$, frases, fotos, entre outros artifícios. As redes sociais são uma forma das empresas medirem como o seu produto está sendo avaliado sem precisar desembolsar um valor para fazer pesquisa de mercado. Os usuários comentam sobre o produto utilizado e falam se gostaram ou não e muitas vezes sugerem melhorias. As empresas podem fazer uma análise de sentimento, as quais coletam e analisam as palavras usadas para descrever o produto que expressa seu sentimento.

A imagem da marca percebida através das avaliações dos consumidores pode gerar uma vantagem competitiva para a empresa. Com esse pensamento, estabelecimentos de comida produziram esforços para criar uma identidade

\footnotetext{
${ }^{3}$ Lovemark significa vínculo do consumidor e empresa que supera o racional. Um sentimento de amor (ROCK CONTENT, 2020).

${ }^{4}$ Emoticons significam figuras que expressam o sentimento ou expressão facial no mundo online (DICIONÁRIO DE INFORMÁTICA, 2014)
} 
diferente, a fim de se destacar da concorrência (BAO et. al., 2011, p.220-226, apud LIMA \& CARLOS, 2018, p.5).

\subsection{Influências Sociais}

Essa seção tem como objetivo explicar os fatores sociais que podem influenciar no processo de compra dos consumidores. Todo ser humano é influenciado de alguma forma, por vários grupos. A cultura que a pessoa está envolvida, a família de cada um, as subculturas que pertence, grupo de amigos e até mesmo a classe social influenciam direta ou indiretamente o cliente (CHURCHILL JR \& PETER, 2012). Para o presente estudo somente foram considerados os grupos de referência, uma vez que estamos abordando o assunto de influência de indivíduos uns sobre os outros dentro da plataforma do Instagram. Dessa forma, o foco a ser analisado será a influência que o grupo pode ter na tomada de decisão dos consumidores.

\subsubsection{Influência dos grupos de referência}

A maior influência que um consumidor recebe é a de um grupo ou de uma pessoa. Cada indivíduo pertence a um grupo que possui seus hábitos e preferências. Por sermos animais sociais temos a necessidade de agradar e nos sentir parte do conjunto. Cada um tem grupos de referências diferentes e cada um deles exerce poder social sobre o indivíduo, o qual tem a competência de alterar as atitudes dos outros (COHEN\& GOLDEN, 1972, p. 54-59, apud SOLOMON, 2016, p.367). Para Churchill Jr e Peter (2012), o grupo de referência é utilizado como um guia de comportamento pelos indivíduos em determinadas situações. Esses grupos são utilizados como uma comparação de comportamentos, atitudes e valores (SCHIFFMAN\& KANUK, 2000).

De acordo com Churchill Jr e Peter (2012), existem alguns tipos de grupos de referência que influenciam nos pensamentos, comportamentos e até mesmo em sentimentos. O primeiro é o grupo de referência primário, o qual o consumidor tem contato diretamente, por exemplo, amigos íntimos e família. Já o grupo de referência secundário não tem um contato face a face, assim, não é tão próximo como o grupo anterior, mas influenciam da mesma maneira. Para Leon Schiffman e Leslie Kanuk (2000), a diferença desses dois tipos é dada pela frequência com que as pessoas interagem com os grupos. É possível perceber que o primeiro 
grupo, por serem pessoas mais próximas, provavelmente irá interagir com mais frequência com os indivíduos se comparados com o grupo secundário. Além disso, Churchill Jr e Peter (2012) afirmam que os grupos de associação são aqueles que o indivíduo é membro e os grupos de aspiração são os que ele deseja estar em algum momento. Por fim, os autores cometam também que existem os grupos dissociativos, que são aqueles que o consumidor quer manter distância (CHURCHILL JR \& PETER, 2012). Existem os grupos que o indivíduo não tem contato direto, como, por exemplo, pessoas famosas, mas que influenciam tanto quanto os outros grupos mencionados anteriormente. Eles geram grande credibilidade ao fazer uma propagando de um produto, o que leva muitos consumidores a comprar (SCHIFFMAN \& KANUK, 2000).

Segundo Schiffman e Kanuk (2000), os grupos de referência também podem oferecer grande credibilidade e são capazes de modificar o comportamento do consumidor. Eles dão a oportunidade de uma empresa ficar mais conhecida, chamando a atenção dos consumidores potenciais para ela. A influência desse grupo consegue reduzir o risco percebido no momento de compra pelo consumidor, já que o argumento usado por alguém do grupo pode mostrar que existe fundamento ao comprar determinado produto ou marca.

\subsubsection{Influência do Instagram}

As redes sociais são um meio utilizado por todos e, consequentemente, uma nova maneira de influência no processo de tomada de decisão. Segundo Rita Santos (2016), a rede social pressupõe uma interação entre pessoas com perfis de seu interesse e amigos através de mensagens que podem variar de vídeos e imagens a textos. Na mesma linha, Beatriz Cleto (2019) comenta que as redes sociais podem ser encaradas como uma base de conteúdos partilhados, de maneira que facilite o acesso a todos. Assim, de acordo com a autora, dado que elas são um portal para adquirir informação durante o processo de tomada de decisão, é possível dizer que as redes sociais são um elemento influenciador.

À medida que o mundo mudou para a mídia social, os consumidores olham para os outros consumidores para decidir suas compras. Em vez de olhar para as empresas, como era feito no passado, agora eles olham uns para os outros e seus influenciadores preferidos. (ADWEEK, 2015 apud SMITH, 2018 - tradução livre ${ }^{5}$.

\footnotetext{
5 "As the world has shifted to social media, consumers look at fellow consumers to inform their purchasing decisions. Instead of looking at companies, as they did in the past, they now look at each other and at their favorite personalities".
} 
O Instagram é uma das maiores redes sociais e por consequência uma das redes com maior potencial de influência. Criado com o objetivo de compartilhar fotos e vídeos em tempo real, após dois anos do lançamento em 2010, o aplicativo tinha mais de 100 mil usuários (INSTAGRAM, 2018 apud CLETO, 2019). Depois de alguns anos de uso por uma grande parcela da população mundial, ele expandiu de rede social para uma ferramenta de negócio, onde diversas empresas utilizam o espaço para divulgar seu produto, principalmente por meio de influenciadores digitais ${ }^{6}$. A rede social, por ser acessada do celular, permite estar no cotidiano de forma rápida e atrativa, onde esses influenciadores podem divulgar o produto por meio de posts e stories ${ }^{7}$. As companhias utilizam essas pessoas para representar seus produtos, porque clientes sentem mais confiança quando eles olham outra pessoa utilizando e aprovando, do que na empresa em questão (CLETO, 2019).

O mundo dos influenciadores digitais é imenso. Eles são muitas vezes vistos como peritos no assunto abordado através da plataforma online, podendo se referir a diversos assuntos, como beleza, culinária, entretenimento, e assim por diante. As marcas visam à quantidade de seguidores e o engajamento deles com o influenciador. O usuário olha para o influenciador como outro consumidor do produto ou mesmo como um amigo, por isso tem a sensação de segurança na hora da compra (SANTOS et al., 2016).

Blogs que compartilham seus interesses entre seus seguidores
podem ser considerados como um dos principais
impulsionadores e facilitadores das mudanças de
relacionamento de marca do consumidor (UZUNOGLU \& KIP,
2014, p.592-602, apud BASSO, 2019, p.39).

A influência das ações das mídias sociais nos consumidores de restaurantes é visível. O uso das plataformas online como forma de divulgação, tanto da marca quanto do produto, impacta tanto na intenção de compra quanto na imagem da organização. O setor de restaurantes tem ainda uma baixa adesão a esse tipo de divulgação, entretanto os estabelecimentos que utilizam esse tipo de estratégia se beneficiam e tendem a influenciar outros locais a usarem (KIM et al., 2015).

\footnotetext{
${ }^{6}$ Influenciadores Digitais são pessoas que têm a capacidade de influenciar outras pessoas a tomarem decisões, seja estilo de vida ou consumo (ROCHA, s.d.)

7 Post - Postagem em inglês. Stories - Recurso do Instagram para publicar fotos ou vídeos, que ficam expostos apenas por 24h. https://duvidas.dicio.com.br/postagem-ou-post/
} 


\section{Metodologia}

Este capítulo tem por objetivo informar sobre as diversas decisões acerca da forma como a pesquisa foi feita.

O capítulo está dividido em quatro seções que informam, respectivamente, sobre o método de pesquisa utilizado, como foi feita a coleta das informações, sua análise e as limitações que do estudo. Cada uma dessas etapas foi de suma importância para a conclusão do estudo, apresentado do quinto capítulo.

\subsection{Método de pesquisa utilizado}

A pesquisa tem o intuito de descobrir respostas para os problemas a partir da implicação de procedimentos científicos (GIL, 2008). Nesse estudo foi utilizado o método de pesquisa qualitativa exploratória, a qual tem como principal finalidade esclarecer ideias tendo em vista o problema. A pesquisa foi feita com o intuito de compreender de que maneira os consumidores são influenciados na escolha de um restaurante por meio do uso do Instagram.

Segundo Antonio Gil (2008), a pesquisa exploratória apresenta menos rigidez no planejamento com entrevistas não padronizadas. Para esse estudo, foram realizadas entrevistas informais e pessoais que, segundo o autor, oferecem uma visão mais similar do problema pesquisado, deixando aberto para o entrevistado se expressar da melhor maneira e abordar outras questões, se for 0 caso (GIL, 2008).

\subsection{Coleta de informações}

O processo de coleta de informação é fundamental para a pesquisa, já que sem ela é impossível fazer qualquer conclusão. Como dito anteriormente, foram selecionados para esse estudo jovens cariocas, entre vinte e trinta anos, que comam fora de casa no mínimo duas vezes por mês. Por uma questão de acessibilidade, a autora decidiu entrevistar pessoas conhecidas.

Segundo Gil (2008), as pessoas a serem entrevistadas precisam ser bem recebidas para uma entrevista bem desenvolvida. Dessa forma, foi postado na 
rede social da entrevistadora sobre o estudo e pedindo para que indivíduos, que se sentissem à vontade e se encaixassem no perfil, se candidatassem a participar da pesquisa. $O$ intuito dessa forma de abordagem foi não ter uma aproximação de surpresa, pois, de acordo com Gil (2008), entrevistados pegos de surpresa demandam muito mais habilidade na condução da entrevista, o que pode influenciar nas respostas. As vinte primeiras pessoas que aceitaram participar do estudo foram entrevistas por vídeo chamada.

Ao início da conversa é importante falar amistosamente, conversando sobre qualquer tema, para que o entrevistado fique mais descontraído e ocorra a quebra de gelo. Além disso, é de suma importância dizer quais os fins da pesquisa e que seu caráter é acadêmico e confidencial (GIL, 2008). A partir disso, toda ligação foi iniciada com uma conversa despojada e, então, indicado os fins da pesquisa. $O$ fato de os entrevistados serem pessoas conhecidas ajudou nesse processo.

Para evitar que assuntos relevantes não fossem abordados, foi criado um roteiro de entrevista, que se encontra no apêndice. Conforme Gil (2008), em entrevistas semiestruturadas, as perguntas dependem do contexto da conversa, porém são necessárias perguntas minimamente padronizadas para que as respostas possam ser comparadas. As entrevistas realizadas foram feitas em forma de conversa, então muitos dos entrevistados responderam de forma e ordem diferente, porém nada que afete a conclusão. Houve um cuidado por parte da autora na abordagem de respostas que não fossem completamente respondidas, tentando abordar novamente o assunto sem sugestões ou exemplos, pois, de acordo com Gil (2008), indagações que não apresentem neutralidade, como exemplos, podem influenciar diretamente na resposta do entrevistado, alterando assim o resultado.

A melhor forma de registrar as entrevistas de uma pesquisa é através de anotações e gravações, sempre com consentimento do entrevistado, e tomando cuidado para que a pessoa não se sinta desconfortável (GIL, 2008). As entrevistas desse estudo foram todas gravadas e ao longo de cada uma foram feitas anotações consideras importantes, com consentimento dos entrevistados. Após cada entrevista, as anotações foram revisadas e organizadas. A todo o momento da entrevista foi tomado cuidado para que as pessoas não se sentissem desconfortáveis com a falta de atenção momentânea, na situação de registro das respostas.

As entrevistas desse estudo foram feitas com jovens, moradores da cidade do Rio de Janeiro, entre 20 e 30 anos, que tem o hábito de utilizar o aplicativo do 
Instagram e fazerem refeições fora de casa ao menos duas vezes por mês. A pesquisa delimitou o "comer fora de casa" a apenas refeições que, mesmo sendo do dia a dia, o entrevistado tenha o poder de escolha do restaurante.

Inicialmente as entrevistas estavam programadas para serem feitas presencialmente, porém com a pandemia do Covid-19 no Brasil e a instauração da quarentena, elas foram feitas via ligação de vídeo.

\subsection{Tratamento e análise dos dados}

A análise dos dados de uma pesquisa qualitativa depende muito do estilo do pesquisador, já que não há fórmulas nem receitas como nos estudos quantitativos, porém apresentam três etapas de análise: redução, apresentação e conclusão. A primeira consiste na conversão dos dados originais em sumários organizados. A apresentação define categorias de análise, definidas na etapa anterior, e a etapa de conclusão revisa os dados (GIL, 2008).

Primeiramente, foi preciso separar as informações relevantes para o estudo em grupos, que fizessem sentido com o objetivo final, simplificando os dados obtidos através das entrevistas. Em seguida, de acordo com a etapa de apresentação, foi feita uma nova organização dos dados e logo em seguida, na parte de conclusão, a revisão dos dados analisados para que consiga chegar a um desfecho.

Segundo Gil (2008), o processo de análise e interpretação dos dados em uma pesquisa qualitativa são feitos em conjunto. Todo o processo de organização dos dados coletados nas entrevistas foi sendo interpretado conjuntamente, assim as conclusões sobre o estudo foram observadas de acordo com a organização das respostas.

\subsection{Limitações do método}

O método de entrevista escolhido para esse estudo tem diversas vantagens, mas limitações também. A etapa de coleta de dados pode ser prejudicada de acordo com as entrevistas. Caso os entrevistados não respondam com explicações ou o entrevistador utilize o meio de, inconscientemente, induzir uma resposta, a conclusão pode sofrer impactos. Há a possibilidade de viés do entrevistador na coleta e na análise das informações, assim como do entrevistado nas respostas que fornece (GIL, 2008). 
É valido ressaltar que como o grupo de respondentes foi escolhido por meio do critério de acessibilidade, há também chances de tendenciosidade pela seleção do grupo de respondentes, já que a pesquisa foi proposta apenas para um público que possui características próprias. 


\section{Apresentação e análise dos resultados}

Este item organizado em três seções apresenta e discute os principais resultados alcançados, analisando suas implicações.

A primeira parte descreve um pouco sobre o perfil dos entrevistados da pesquisa, entendendo como são seus hábitos de consumo de restaurante. $\mathrm{Na}$ sessão seguinte, encontra-se o resultado das demais perguntas investigadas e, por último, a análise com relação à teoria exposta nas sessões anteriores.

\subsection{Perfil dos Entrevistados}

Para a pesquisa exploratória foram feitas 20 entrevistas com indivíduos entre 21 e 25 anos, moradores da cidade do Rio de Janeiro. A maioria dos respondentes era do sexo feminino.

A maioria dos entrevistados ainda está cursando a faculdade e não trabalha nem faz estágio, o que se pode concluir que provavelmente não vivem de renda própria. Dentre os estudantes, são poucos os que utilizam a rede pública de ensino, a maioria estuda em universidades privadas da cidade.

Durante a entrevista foi questionada a quantidade de vezes que cada um comia fora de casa por mês. Grande parte dos respondentes interpretava "comer fora de casa" como um jantar ou almoço não habitual. Os primeiros dois entrevistados questionaram se incluíam na contagem refeições habituais, como almoço durante a semana de trabalho, e foi respondido que se eles tivessem o poder de escolha dos estabelecimentos, contaria. Para que não houvesse nenhum tipo de dúvida, nas entrevistas seguintes foi feito esse comentário logo em seguida da pergunta. Como dito no capítulo anterior, delimitamos o "comer fora de casa" apenas para refeições as quais a pessoa tenha o poder de escolha do local. A quantidade de refeições feitas fora de casa para cada entrevistado oscilou bastante, já que isso depende do estilo de vida que cada um possui. Os resultados variaram entre duas e 30 vezes por mês, conforme pode ser visto no Quadro 1 a seguir. 
Quadro 1: Dados dos Entrevistados

\begin{tabular}{|c|c|c|c|}
\hline $\begin{array}{c}\text { Nome dos } \\
\text { Entrevistados }\end{array}$ & Idade & Profissão & $\begin{array}{c}\text { № de vezes que costuma } \\
\text { comer fora de casa, por } \\
\text { mês }\end{array}$ \\
\hline Entrevistado 1 & 25 & Advogado & 20 \\
\hline Entrevistado 2 & 26 & Advogada & 24 \\
\hline Entrevistado 3 & 23 & Estudante & 10 \\
\hline Entrevistado 4 & 22 & Estudante & 10 \\
\hline Entrevistado 5 & 22 & Estudante & 8 \\
\hline Entrevistado 6 & 23 & Estudante & 15 \\
\hline Entrevistado 7 & 23 & Estudante & 12 \\
\hline Entrevistado 8 & 23 & $\begin{array}{l}\text { Assistente de } \\
\text { Produção }\end{array}$ & 20 \\
\hline Entrevistado 9 & 23 & Estudante & 4 \\
\hline Entrevistado 10 & 21 & Estudante & 24 \\
\hline Entrevistado 11 & 25 & Estudante & 3 \\
\hline Entrevistado 12 & 21 & Estudante & 4 \\
\hline Entrevistado 13 & 22 & Estudante & 24 \\
\hline Entrevistado 14 & 25 & Estudante & 2 \\
\hline Entrevistado 15 & 24 & Estudante & 12 \\
\hline Entrevistado 16 & 25 & Estudante & 8 \\
\hline Entrevistado 17 & 23 & Estudante & 8 \\
\hline Entrevistado 18 & 23 & Estudante & 30 \\
\hline Entrevistado 19 & 25 & Estudante & 30 \\
\hline Entrevistado 20 & 23 & Estudante & 5 \\
\hline
\end{tabular}

\subsection{Uso da rede social}

Após terem sido feitas as perguntas introdutórias para traçar o perfil de cada entrevistado, seguiu-se às perguntas centrais do estudo. Foi perguntado, inicialmente: "Possui conta no Instagram?" e "Que tipo de perfil você mais gosta de seguir? Por que isso te interessa?". Apesar das respostas terem variado bastante, todos seguem algum tipo de influenciador da sua área de interesse. De acordo com Santos et al. (2016), os influenciadores passam uma sensação de 
segurança ao mostrar um produto, o que leva o consumidor a minimizar os riscos percebidos.

Após essa introdução, foi questionado quanto tempo cada um passava utilizando a plataforma. Como o aplicativo tem a possibilidade desse número ser visualizado pelo usuário, todos os entrevistados foram consultá-lo ao invés de passar sua percepção. A variação das respostas foi de 25 a 300 minutos, as mulheres declarando passar mais tempo do que os homens.

Em seguida, foi questionado se os entrevistados seguiam algum perfil de comida e apenas um dos 20 entrevistados não seguiam algum perfil do gênero. Segundo Lima e Carlos (2018), o setor de restaurantes ainda tem uma baixa adesão ao uso das mídias sociais como forma de divulgação, entretanto, o universo de influenciadores digitais desse gênero tem crescido. Cleto (2019) diz que as empresas utilizam esses influenciadores, já com credibilidade, para falarem da sua marca.

Para os entrevistados, três aspectos chamam atenção nos perfis de comida que seguem: aparência, sinceridade e variedade. Essas três características, segundo os entrevistados, fazem despertar algum interesse que os leva a acompanhar e visualizar as postagens feitas pelos perfis. O Instagram, segundo Cleto (2019), é uma plataforma que permite, por meio de fotos e vídeos, fácil e rápido acesso com milhões de usuários. Para se destacar, é preciso mostrar algo diferente e que chame atenção. Além disso, o fato de terem confiança nos influenciadores que cada um segue, tendo eles como amigos, segundo Santos et al. (2019), fazem com que a questão da sinceridade seja um ponto importante. As pessoas acabam criando uma relação com esses influenciadores e os tem como referência, tirando dúvidas e pedindo opinião.

Sempre pergunto o que acharam por mensagem. Confio bastante na opinião deles e acho que a sinceridade deles é essencial (ENTREVISTADO 4, 2020 - 22 anos).

Costumo perguntar no privado para os perfis quais restaurantes eles escolheriam para uma ocasião específica (ENTREVISTADO 10, 2020 - 21 anos).

Odeio quando falam bem só porque foram pagos, perde a minha confiança e acabo parando de seguir (ENTREVISTADO 1, 2020 -25 anos).

A plataforma foi criada com o objetivo de divulgar fotos e vídeos, mas hoje tem um papel maior. As pessoas utilizam o Instagram como forma de pesquisa para determinado assunto (CLETO, 2019). De acordo com as entrevistas feitas, poucos respondentes afirmaram não utilizar a rede social com 0 intuito de 
pesquisar restaurantes. Eles disseram ser influenciados apenas por amigos na hora da decisão. Os outros entrevistados responderam que o Instagram os influência de diversas maneiras, sendo através de publicações de fotos e vídeos nos perfis de comida, por pesquisa de determinado local ou até mesmo por publicidade dos perfis dentro da plataforma. Algumas respostas interessantes sobre $\mathrm{o}$ assunto foram:

Sempre que quero saber mais sobre um restaurante, entro no Instagram e procuro dele para ver as fotos dos pratos (ENTREVISTADO 3, 2020 - 23 anos).

O Instagram é o meio que eu utilizo para conhecer os restaurantes novos do Rio (ENTREVISTADO 4, 2020 - 22 anos).

Queria conhecer um restaurante que tinha ouvido falar e entrei no @gordinhasatoa para ver se tinham resenha sobre ele (ENTREVISTADO 6, 2020 - 23 anos).

É muito bom entrar e saber se tem opções vegetarianas que eu possa comer (ENTREVISTADO 20, 2020 - 23 anos).

Já abri o Instagram diversas vezes para pensar em ideias do que e onde comer (ENTREVISTADO 2, 2020 - 26 anos).

Tenho o costume de entrar no @jacanossadecadadia para ver restaurantes e a opinião sobre eles (ENTREVISTADO 5, 2020 22 anos).

\subsection{Processo de tomada de decisão}

O processo de tomada de decisão de decisão envolve cinco fases que consistem em reconhecer o problema, buscar, avaliar o produto, escolher e avaliação pós compra (SOLOMON, 2016). Ao observar as respostas dos entrevistados dessa pesquisa exploratória, compreendendo que muitos associam "sair para comer" como algo não habitual - podendo, assim, escolher um lugar específico -, as pessoas investigam sobre as possibilidades de restaurantes, avaliam a partir das críticas na plataforma e escolhem um local. Outro fator que influencia nesse momento é que muitas das escolhas podem gerar um custo relativamente alto, por isso a pesquisa sobre o lugar é tão importante para os entrevistados - quanto maior o preço e características complexas, o tempo investido na pesquisa é maior.

Sempre que quero ir a algum restaurante, procuro indicações e vou em alguns perfis que falaram sobre ele para ver fotos dos pratos e preços (ENTREVISTADO 17, 2020 - 23 anos).

Quando quero conhecer um restaurante novo, abro o Instagram para pesquisar (ENTREVISTADO 15, 20220 - 24 anos). 
De acordo com Solomon (2016), o primeiro estágio do processo de tomada de decisão ocorre quando é percebida uma diferença dos estados ideal ou real, reconhecendo o problema pela necessidade ou pela oportunidade. No caso do estudo, que pesquisou sobre a influência do Instagram no processo de tomada de decisão dos consumidores ao escolher um restaurante, o estado ideal sempre é aumentado. Uma boa foto precisa de um bom ângulo, com uma boa iluminação, para passar para os seguidores exatamente a mesma sensação de quem está comendo. Ao olhar para uma foto ou vídeo de alguma comida que as chame atenção, elas sentem vontade de comer, fazendo com que a reta mostrada na figura 2 suba.

Quando tem uma foto muito bonita, como uma pizza brilhante, sempre me dá vontade de comer (ENTREVISTADO 10, 2020 21 anos).

Uma foto hambúrguer do TT Burger sempre me dá vontade de comer, mesmo se tiver acabado de almoçar (ENTREVISTADO 14,2020 - 25 anos).

Às vezes é chato ficar olhando muito esses Instagrams que dá vontade de comer, as comidas são sempre muito bonitas (ENTREVISTADO 18, 2020 - 23 anos).

O passo seguinte desse processo é a busca de informação, a qual consiste em buscar dados (SOLOMON, 2016). Santos et al. (2016) comentam que os influenciadores digitais são vistos, por seus seguidores, como peritos do assunto por eles abordado. Segundo os comentários dos entrevistados, é nítida a influência da plataforma na hora da escolha, sendo essa influência através de influenciadores ou perfis institucionais. Algumas pessoas comentaram que além do Instagram, os comentários e opiniões de amigos e familiares têm um grande peso.

Estava na dúvida entre comer hambúrguer ou pizza. Entrei no Instagram para decidir (ENTREVISTADO 1, 2020 - 25 anos).

Queria comer um hambúrguer bem gostoso. Entrei nos perfis de comida que eu sigo para ter ideia e opinião de lugares (ENTREVISTADO 2, 2020 - 26 anos).

Sempre que não sei onde ir, entro nos perfis de influenciadores de comida que eu sigo para ver (ENTREVISTADO 15, 2020 - 24 anos).

Sempre via vários Instagram falando do Bar Itália em Nova lorque. Quando viajei, fui no restaurante no primeiro dia (ENTREVISTADO 20, 2020 - 23 anos).

O Instagram é decisivo na minha escolha. Antes de ir no restaurante, vejo 0 perfil dele e os comentários (ENTREVISTADO 19, 2020 - 25 anos). 
Eu sigo perfis e salvo algumas indicações que acho interessantes, mas a maioria das vezes decido o restaurante por indicação de algum amigo que já foi (ENTREVISTADO 9, 23 anos).

Já selecionei o restaurante no Instagram, mas pedi uma segunda opinião para minha amiga (ENTREVISTADO 13, 2020 -22 anos).

A avaliação das alternativas é diferente para cada indivíduo, já que pesos e medidas são individuais (SCHIFFMAN\& KANUK, 2000). Lima e Carlos (2018) complementam que a imagem da marca através da avaliação dos consumidores pode gerar um grande diferencial para os estabelecimentos de comida. Quando um usuário é impactado com uma publicação e conhece o nome do restaurante, é maior a chance de chamar mais atenção. Durante as entrevistas, foi questionado se lembravam algum perfil sobre o assunto e todos lembravam algum, sendo eles influenciadores ou perfis institucionais. No quadro 2 estão listados os perfis que foram comentados durante as entrevistas. A maioria são perfis de influenciadores de comida, isso é, aqueles que indicam e fazem comentários sobre restaurantes, como por exemplo o@jacanossadecadadia,@canaldoscacadores, @letseat, @comercomer etc. Já outros, são perfis institucionais dos próprios restaurantes, como o@gurume, @outback e @passaroverde. Alguns entrevistados comentaram que mesmo pesquisando nos perfis de influenciadores, gostam de ir aos perfis dos restaurantes para olhar. 
Quadro 2: Perfis mencionados durante as entrevistas

\begin{tabular}{|l|}
\hline Perfis mencionados nas entrevistas \\
\hline @jacanossadecadadia \\
$@$ letseat \\
$@$ cariocando.gourmet \\
@gordinhasatoa \\
@hamburgaando \\
@bbqspirits \\
@passaroverde \\
@outback \\
@gurume \\
@comercomer \\
@julianaggueiros \\
@gordices101 \\
@canaldoscacadores \\
@menuparadois
\end{tabular}

A decisão de compra é o momento seguinte, o qual o consumidor decide o restaurante que quer comer. Após essa etapa, existe a avaliação pós-compra, que segundo Churchill e Peter (2012), consiste em uma fase onde o consumidor verifica se as expectativas foram atendidas. Esse momento é importantíssimo para os estabelecimentos, já que isso pode fidelizar ou não o cliente e levar ele a fazer comentários bons ou ruins a respeito do local.

Como dito anteriormente, a sinceridade dos perfis é um dos pontos chave, segundo os entrevistados. A partir dela que os seguidores determinaram suas expectativas. Uma avaliação pós-compra negativa de um influenciador pode comprometer uma marca.

Umavezo@jacanossadecadadia postou sobre uma loja de cookie no centro da cidade e fui conhecer. No local não era o que eu imaginava, mas o sabor foi fiel ao post (ENTREVISTADO 10, 2020 - 21 anos).

As fotos e os comentários do Del Plin sempre eram incríveis. Decidi ir conhecer, mesmo sendo longe, e foi péssimo. Atendimento e comida ruins (ENTREVISTADO 7, 2020 - 23 anos). 
Tinha um restaurante de massa que até tinha vontade de conhecer, vi um post falando tão mal que acabei deixando de lado (ENTREVISTADO 3, 2020 - 23 anos).

A figura 3 mostra um exemplo de influenciador contando uma experiência ruim em um restaurante.

Figura 3: Publicação no Instagram sobre experiência negativa de um usuário ao consumir em um restaurante

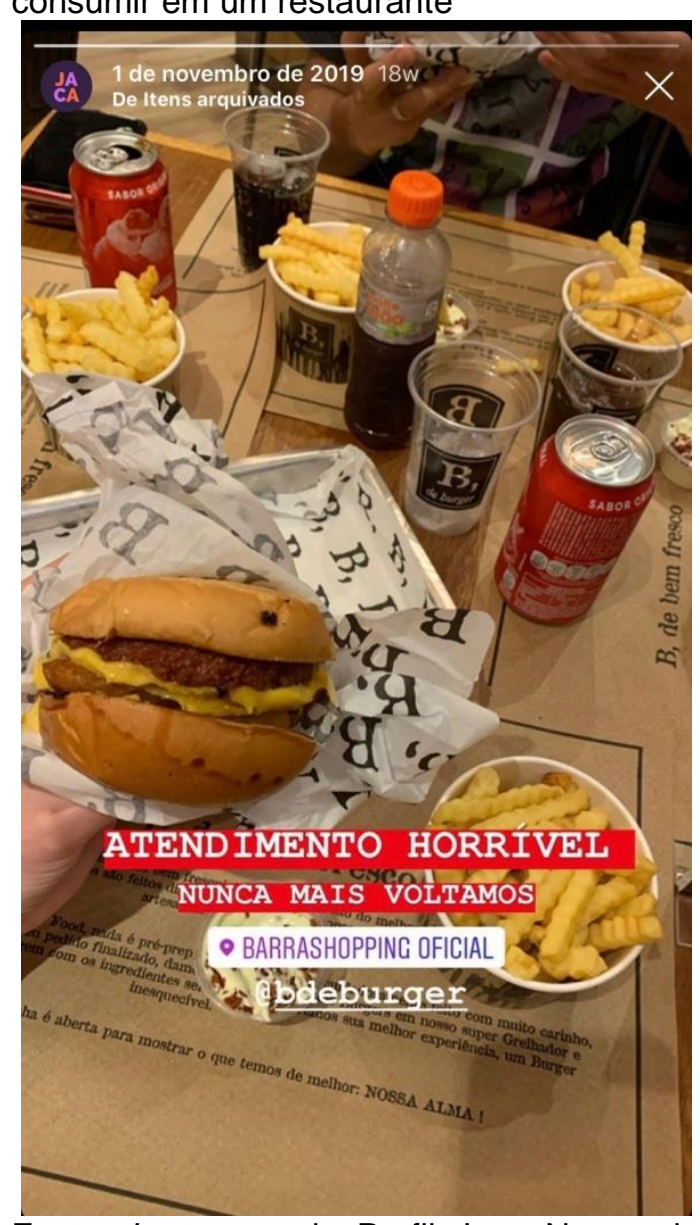

Fonte: Instagram do Perfil Jaca Nossa de

Cada Dia (acessado em novembro de 2019)

Segundo Solomon (2016), as mídias sociais envolvem muita emoção dos usuários, compartilhando sentimentos e momentos, sendo eles positivos ou negativos. Esses sentimentos compartilhados por um influenciador podem fazer com que os seus seguidores tenham mais ou menos vontade de ir conhecer um lugar. Se a pessoa teve uma experiência agradável e comentar isso, pode gerar uma vontade maior do consumidor conhecer.

Todos os perfis que eu sigo falaram que tiveram ótimas experiências no Abraccio. Fui super animada conhecer (ENTREVISTADO 5, 2020 - 22 anos). 
Sempre ouvi falar bem do Tutto Nhoque e vi um post falando tão bem que tive que conhecer (ENTREVISTADO 8, 2020 - 23 anos).

Estava vendo os perfis que eu sigo e vi o post sobre o Grado Restaurante. No final de semana seguinte, eu fui conhecer o restaurante (ENTREVISTADO 7, 2020 - 23 anos).

A maioria dos entrevistados é influenciada pelo Instagram em alguma etapa do processo de tomada de decisão de consumo de restaurantes. Nota-se também, pelas respostas obtidas, que a plataforma é um meio de pesquisa bastante utilizado, sendo uma das principais fontes. 


\section{Conclusões}

O estudo teve como objetivo entender de que maneira ocorrem as influências sociais por meio do Instagram na tomada de decisão de restaurantes por consumidores jovens

Dentro dos principais achados, pode-se destacar a importância da plataforma como divulgadora de informação, a influência do visual da foto na hora de despertar o interesse e a conexão que o usuário cria com outros perfis, acreditando neles como se fossem íntimos. A maioria dos entrevistados utiliza a plataforma como fonte de pesquisa de restaurantes, seguindo influenciadores de comida, perfis dos próprios restaurantes ou até mesmo só entrando nesses perfis para saber mais sobre o local que desejam ir. Além disso, entendem que uma boa foto, isso é, com iluminação e ângulo corretos, gera desejo e colabora no processo de tomada de decisão.

\subsection{Implicações Gerais}

A plataforma do Instagram é um local onde diversas pessoas vão atrás de informação, principalmente no contexto de restaurantes. A faixa etária estudada é muito influenciada por um post ou até mesmo uma foto nos stories de um perfil, diferente de outras gerações. Assim, é importante que os donos dos estabelecimentos tenham conta do seu restaurante de forma que publiquem fotos que chamem atenção e tenham um perfil organizado, que facilite ao consumidor procurar o que precisa. Ademais, procurar deixar o perfil movimentado com certa frequência de posts para que sempre esteja aparente para os seus clientes se mostra como uma boa estratégia.

Outra recomendação importante de se destacar é utilizar parcerias com influenciadores que sejam sinceros e realmente gostem do seu produto, para que na hora que forem vender não aparentar falsidade. Compreender quem é o seu público e achar um influenciador que esteja compatível com ele, deixando que a propaganda fique algo natural, é uma ação eficiente. Quanto menos parecer um publipost, mas sensação de credibilidade terá para o público. 
Além disso, os próprios influenciadores devem fechar parceria que realmente acreditam e utilizam, para não ficar forçado e perder a confiança. Antes de falar que um restaurante é bom porque foi pago para isso, ir ao local e ver se é condizente com que o vai falar para os seguidores é conveniente.

Os profissionais de marketing que trabalham dentro dessa indústria precisam estar atentos às mudanças do mundo digital. O Instagram hoje é uma plataforma de destaque, entretanto, em poucos meses podemos ter outra plataforma crescendo. O desafio é como se destacar nesses ambientes, estando presente com a marca. Uma imagem da marca positiva pode gerar vantagem competitiva (LIMA \& CARLOS, 2018).

\subsection{Sugestões de futuras pesquisas}

Diante do então trabalho, recomenda-se como futuras pesquisas o aprofundamento no estudo sobre o papel dos influenciadores dentro desse mercado, tendo em vista que é um segmento que já apresenta ter relevância para essa indústria. Uma sugestão para futuras pesquisas é fazer entrevistas com outro tipo de público, sendo ele mais velho ou mais novo, buscando entender como é a influência para eles e como eles afetam seus grupos sociais. Além disso, é possível pensar especificamente no consumo de delivery de restaurantes e se o processo de tomada de decisão é o mesmo, tendo em vista que não existe o ambiente físico do restaurante. 


\section{Referências Bibliográficas}

AGRELA, L. Estes são os dez países que mais usam o Instagram. Exame, São Paulo, 12 mai. 2019. Disponível em: <https://exame.com/tecnologia/estes-sao-osdez-paises-que-mais-usam-o-instagram/>. Acesso em: 12 de junho de 2020.

ARORA, R. Validation of a S-O-R Model for situation, enduring, and response components of involvement. Journal of Marketing Research, v. 19, n. 4, p. 505516, nov. 1982.

BASSO, L. C. O efeito de micro-digital influencers no comportamento de compra no Instagram em contextos de produtos de moda. Caxias do Sul, 2019.84 p. Trabalho de Conclusão de Curso (Graduação em Administração) Área do Conhecimento de Ciências Sociais: Universidade de Caxias do Sul.

BBC NEWS BRASIL. Brasil é 2ºm ranking de países que passam mais tempo em redes sociais. Época Negócios, 06 set. 2019. Disponível em: <https://epocanegocios.globo.com/Tecnologia/noticia/2019/09/brasil-e-2-emranking-de-paises-que-passam-mais-tempo-em-redes-sociais.html>. Acesso em: 12 de junho de 2020.

BBC NEWS BRASIL. Como o Instagram está revolucionando a indústria de restaurantes. Época Negócios, 12 nov. 2018. Disponível em: $<$ https://epocanegocios.globo.com/Tecnologia/noticia/2018/11/como-oinstagram-esta-revolucionando-industria-de-restaurantes.html>. Acesso em: 11 de junho 2020.

CHURCHILL JR., G. A.; PETER, J.P. Marketing: Criando valor para o cliente. 3. ed. São Paulo: Editora Saraiva. 2012.

CLETO, B. F. O impacto dos Influencers no processo de decisão e compra no Instagram. Lisboa, 2019.117 p. Dissertação (Mestrado em Gestão de Empresas) - Escola de Ciências Económicas e das Organizações: Universidade Lusófona de Humanidades e Tecnologias.

DEVISATE, I. Performance do food service. Food Service News, 14 set. 2019. Disponível em: <https://www.foodservicenews.com.br/performance-do-foodservice/>. Acesso em: 11 de junho de 2020. 
DICIONÁRIO DE INFORMÁTICA. [Letra] E. Dicionário de Informática e Negócios, 2014. Disponível em: <https://www.dicweb.com/ee.htm>. Acesso em: 13 de junho de 2020.

DINO. Consumo: $74 \%$ das pessoas compram de acordo com as influências das mídias sociais. Exame, 03 abr. 2018. Disponível em: $<$ https://exame.com/negocios/dino old/consumo-74-das-pessoas-compram-deacordo-com-as-influencias-das-midias-sociais/>. Acesso em: 13de junho de 2020. ENTREVISTADO 1. Entrevistado 1: depoimento [mai. 2020]. Entrevistadores: A. Rocha. Rio de Janeiro (online), 2020. Entrevista concedida a Ana Carolina Camilo M. da Rocha.

ENTREVISTADO 2. Entrevistado 2: depoimento [mai. 2020]. Entrevistadores: A. Rocha. Rio de Janeiro (online), 2020. Entrevista concedida a Ana Carolina Camilo M. da Rocha.

ENTREVISTADO 3. Entrevistado 3: depoimento [mai. 2020]. Entrevistadores: A. Rocha. Rio de Janeiro (online), 2020. Entrevista concedida a Ana Carolina Camilo M. da Rocha.

ENTREVISTADO 4. Entrevistado 4: depoimento [mai. 2020]. Entrevistadores: A. Rocha. Rio de Janeiro (online), 2020. Entrevista concedida a Ana Carolina Camilo M. da Rocha.

ENTREVISTADO 5. Entrevistado 5: depoimento [mai. 2020]. Entrevistadores: A. Rocha. Rio de Janeiro (online), 2020. Entrevista concedida a Ana Carolina Camilo M. da Rocha.

ENTREVISTADO 6. Entrevistado 6: depoimento [mai. 2020]. Entrevistadores: A. Rocha. Rio de Janeiro (online), 2020. Entrevista concedida a Ana Carolina Camilo M. da Rocha.

ENTREVISTADO 7. Entrevistado 7: depoimento [mai. 2020]. Entrevistadores: A. Rocha. Rio de Janeiro (online), 2020. Entrevista concedida a Ana Carolina Camilo M. da Rocha.

ENTREVISTADO 8. Entrevistado 8: depoimento [mai. 2020]. Entrevistadores: A. Rocha. Rio de Janeiro (online), 2020. Entrevista concedida a Ana Carolina Camilo M. da Rocha.

ENTREVISTADO 9. Entrevistado 9: depoimento [mai. 2020]. Entrevistadores: A. Rocha. Rio de Janeiro (online), 2020. Entrevista concedida a Ana Carolina Camilo M. da Rocha.

ENTREVISTADO 10. Entrevistado 10: depoimento [mai. 2020]. Entrevistadores: A. Rocha. Rio de Janeiro (online), 2020. Entrevista concedida a Ana Carolina Camilo M. da Rocha. 
ENTREVISTADO 13. Entrevistado 13: depoimento [mai. 2020]. Entrevistadores: A. Rocha. Rio de Janeiro (online), 2020. Entrevista concedida a Ana Carolina Camilo M. da Rocha.

ENTREVISTADO 14. Entrevistado 14: depoimento [mai. 2020]. Entrevistadores: A. Rocha. Rio de Janeiro (online), 2020. Entrevista concedida a Ana Carolina Camilo M. da Rocha.

ENTREVISTADO 15. Entrevistado 15: depoimento [mai. 2020]. Entrevistadores: A. Rocha. Rio de Janeiro (online), 2020. Entrevista concedida a Ana Carolina Camilo M. da Rocha.

ENTREVISTADO 17. Entrevistado 17: depoimento [mai. 2020]. Entrevistadores: A. Rocha. Rio de Janeiro (online), 2020. Entrevista concedida a Ana Carolina Camilo M. da Rocha.

ENTREVISTADO 18. Entrevistado 18: depoimento [mai. 2020]. Entrevistadores: A. Rocha. Rio de Janeiro (online), 2020. Entrevista concedida a Ana Carolina Camilo M. da Rocha.

ENTREVISTADO 19. Entrevistado 19: depoimento [mai. 2020]. Entrevistadores: A. Rocha. Rio de Janeiro (online), 2020. Entrevista concedida a Ana Carolina Camilo M. da Rocha.

ENTREVISTADO 20. Entrevistado 20: depoimento [mai. 2020]. Entrevistadores: A. Rocha. Rio de Janeiro (online), 2020. Entrevista concedida a Ana Carolina Camilo M. da Rocha.

FRIGO, L. B.; POZZEBON, E.; BITTENCOURT, G. O papel dos agentes inteligentes nos sistemas tutores inteligentes. World Congress on Engineering and Technology Education, São Paulo, p. 667-671, mar. 2004.

GIL, A. C. Métodos e Técnicas de Pesquisa Social. 6. ed. São Paulo: Editora Atlas S.A., 2008.

GOULART, L. D.; GONÇALVES, V. V.; LONGO, L. B. F.; VENTURA, R. C. M. O.; SOUZA, R. A. A influência das redes sociais no processo de decisão de compra. Anais do V Seminário Científico do UNIFACIG: Sociedade, Ciência e Tecnologia. Centro Universitário UNIFACIG, n. 5, 2019. Disponível em: $<$ http://pensaracademico.facig.edu.br/index.php/semiariocientifico/article/downloa d/1537/1215>. Acesso em: 13 de junho de 2020.

HOUSTON, M. J.; ROTHSCHILD, M. L. A paradigm for research on consumer involvement. Unpublished Working Paper \#11-77-46, University of WisconsinMadison, jan. 1977. 
KIM, S.; KOH, Y.; CHA, J.; LEE, S. Effects of social media on firm value for US restaurant companies. International Journal of Hospitality Management, v.49, p. 40-46, ago. 2015.

LEITE, C. M. S. C. Instagram e moda: Um panorama do mercado brasileiro. Rio de Janeiro, 2019.49 p. Trabalho de Conclusão de Curso (Graduação em Administração de Empresas) - Departamento de Administração: Pontifícia Universidade Católica do Rio de Janeiro.

LIMA, M. M.; CARLOS, A. L. C. G. A Influência das Mídias Sociais no Consumidor de um Restaurante. Anais do EnANDAP. Curitiba: 2018. Disponível em: <http://legado.fucape.br/ public/producao cientifica/2/A\%20Influência\%20das\%2 OM\%C3\%ADdias\%20SociaiMKT357.pdf>. Acesso em: 13 de junho de 2020.

PEREIRA, R. I. C. As motivações e o envolvimento do consumidor com as marcas do setor vestuário e acessórios - A influência do Instagram. Porto, 2018.109 p. Dissertação (Mestrado em Marketing Digital) - Instituto Superior de Contabilidade e Administração do Porto: Instituto Politécnico do Porto.

ROCHA, Hugo. Tudo sobre Influenciadores Digitais: a melhor ponte entre sua marca e seus clientes. Klickpages, sem data. Disponível em: $<$ https://klickpages.com.br/blog/influenciadores-digitais/>. Acesso em: 13 de junho de 2020.

ROCKET CONTENT. Conheça o conceito de Lovemark e transforme seus clients em amantes da sua marca. Rock Content, 14 jan. 2020. Disponível em: <https://rockcontent.com/blog/lovemark/>. Acesso em: 13 de junho de 2020.

SÁ, P. F. Gabriela Pugliesi no Instagram: influenciadores digitais e a convergência dos meios. Rio de Janeiro, 2017.63 p. Trabalho de Conclusão de Curso (Graduação em Comunicação - Habilitação em Jornalismo) - Escola de Comunicação: Universidade Federal do Rio de Janeiro.

SANTOS, L. Food Service, o que é? Sischef, $01 \mathrm{fev}$. 2018. Disponível em: <https://sischef.com/food-service-o-que-e>. Acesso em: 13 de junho de 2020.

SANTOS, R. S.A influência do Instagram na atitude do consumidor: o caso da LeviStrauss \& Co. Lisboa, 2016. 87 p. Dissertação (Mestrado em Marketing Digital) - Universidade Europeia.

SANTOS, S. M. M.; SILVA, P. P. P.; SANTOS, J. F. Gabriela Pugliesi: uma análise sobre o marketing de influência na rede social Instagram. Anais do XVIII Congresso de Ciências da Comunicação na Região Nordeste. Caruaru (PE): IJ 2 - Publicidade e Propaganda, jul. 2016. Disponível em: <http://www.portalintercom.org.br/anais/nordeste2016/resumos/R52-0157-1.pdf>. Acesso em: 13 de junho de 2020. 
SARAIVA, P. M. Marketing Digital: A utilização das mídias sociais como um canal de comunicação no varejo de moda de Barbalha-CE. Revista Multidisciplinar e de Psicologia, v. 13, n.44, p. 486-507, 2019.

SCHIFFMAN, L. G.; KANUK, L. L. Comportamento do Consumidor. 6. ed. Rio de Janeiro: Editora LTC, 2000.

SILVEIRA, D. Brasileiros estão comendo mais fora de casa e consumindo mais alimentos prontos, diz IBGE. G1, Rio de Janeiro, 04 out. 2019. Disponível em: $\quad<$ https://g1.globo.com/economia/noticia/2019/10/04/brasileiros-estaocomendo-mais-fora-de-casa-e-consumindo-mais-alimentos-prontos-dizibge.ghtml>. Acesso em: 13 de julho 2020.

SMITH, M. The eye-opening influence of Instagram on buying [Infographic]. Impact, 08 dez. 2019. Disponível em: <https://www.impactbnd.com/blog/influenceof-instagram-on-buying-infographic >. Acesso em: 13 de julho de 2020.

SOLOMON, M. R. O comportamento do consumidor: comprando, possuindo e sendo. Tradução de Beth Honorato. 11. ed. Porto Alegre: Bookman, 2016.

SOUZA, P. B. M. O marketing digital sob a perspectiva das mídias sociais como fonte de informação para a decisão de compra no varejo de moda feminina. Belo Horizonte, 2018.63 p. Dissertação (Mestrado em Administração) Faculdade de Ciências Empresariais: Universidade FUMEC.

TAGGART, A. Why you never have enought time, a history. Quartz at Work, 9 mai. 2018. Disponível em: <https://qz.com/work/1272033/why-you-never-haveenough-time-a-history/>. Acesso em: 11 de junho de 2020. 


\section{Apêndice: Roteiro da pesquisa}

Me fale um pouquinho de você...

Qual o seu nome?

Quantos anos você tem?

Você estuda? Onde?

Você trabalha em algum lugar? Com o que trabalha? Você gosta do seu trabalho?

Você costuma comer fora de casa? Quantas vezes por mês?

Você tem conta no Instagram? Sabe quanto tempo passa utilizando-o? Em que situações você mais usa?

Qual tipo de perfil você gosta mais de seguir? Por que isso te interessa?

Você tem o costume de ver algum perfil Instagram de comida? Lembra de algum que goste que possa me dizer? Segue algum? Como você chega até esses perfis - indicação, post de outras pessoas ou empresas...?

O que mais te chama atenção nos perfis de comida dentro da plataforma? O que mais gosta neles? Tem algo neles que lhe desagrada, mesmo que de vez em quando? (pedir para explicar)

Você costuma interagir com eles? De que forma?

Alguma postagem sobre um restaurante te interessou e você foi conhecer? Como foi sua experiência?

Alguma vez você buscou algum perfil específico no Instagram para saber mais sobre algum lugar para comer em que você tinha interesse? Como foi essa situação?

Já passou por alguma situação que você não sabia que lugar escolher para comer e abriu o Instagram para pensar em opções?

Tem alguma sugestão ou crítica para esses perfis de comida no Instagram? 